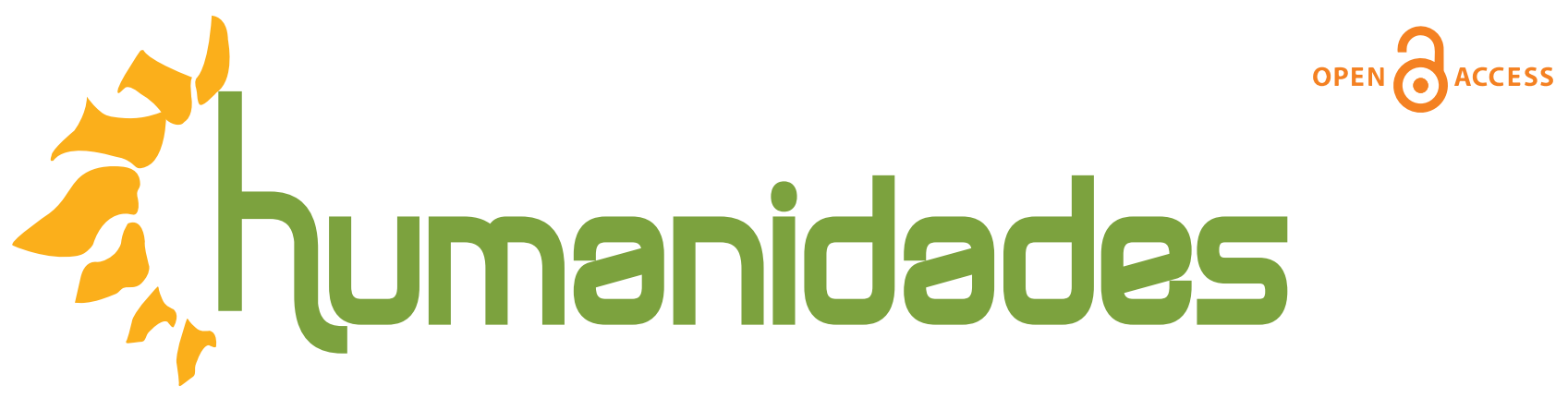

Revista de la Escuela de Estudios Generales, Universidad de Costa Rica

Julio-diciembre, 2019 •Volumen 9, número 2 • EISSN 2215-3934 • pp. 1-20

Recibido: 25-Abril-2019 Aceptado: 13-Junio-2019

\title{
Una aproximación histórico-social a la evolución de los derechos de la comunidad LGBTI+ en México
}

DOI: https://doi.org/10.15517/h.v9i2.37751

\section{José Carlos Vázquez Parra}

Doctor en Estudios Humanísticos

Escuela de Humanidades y Educación, Tecnológico de Monterrey, México

Correo electrónico: jcvazquezp@tec.mx

\section{Domingo Coss y León Coss y León}

Doctor en Ciencias Sociales

Escuela de Humanidades y Educación, Tecnológico de Monterrey, México

Correo electrónico: domingo.coss@tec.mx

\section{Omar Salinas García}

Máster en Gestión Pública Aplicada

Escuela de Ciencias Sociales y Gobierno, Tecnológico de Monterrey, México

Correo electrónico: omar.salinas@tec.mx

Todos los derechos reservados. Universidad de Costa Rica. Esta revista se encuentra licencida con Creative Commons. Reconocimiento-NoComercial-SinObraDerivada 3.0 Costa Rica. Correo electrónico: humanidades@ucr.ac.cr/ Sitio web: http: //revistas.ucr.ac.cr/index.php/humanidades 


\section{Una aproximación histórico-social a la evolución de los derechos de la comunidad LGBTI+ en México}

\section{Resumen}

En un mundo contemporáneo que parece luchar más por la igualdad y el respeto a la diversidad, se puede perder de vista que las conquistas alcanzadas tienen una historia profunda enmarcada por la segregación, el rechazo y los señalamientos, lo cual puede desviarnos de lo que verdaderamente es importante. Por ello, el presente artículo busca hacer una reflexión sobre el desarrollo histórico y social de la lucha y el activismo de la comunidad LGBTI+ en México, englobando su pasado fuertemente religioso y la gran influencia que ha tenido la sociedad internacional en la consecución de mayores derechos para la población mexicana. Como conclusión, se ve la necesidad de enfocarse en una lucha que continúa activa y que, a pesar de las metas alcanzadas, aún tiene objetivos pendientes.

\section{A Historical-Social Approach to the Evolution of the Rights of the LGBTI+ Community in Mexico}

\begin{abstract}
In a contemporary world that seems to fight more for equality and respect for diversity, we can lose sight of the fact that the achieved achievements have a deep history framed by segregation, rejection and accusations, which can deviate us from the what is really important therefore. This article seeks to reflect on the historical and social development of the struggle and activism of the LGBTI+ community in Mexico, encompassing its strongly religious past, and the great influence that international society has had on the achievement of greater rights for the Mexican population. In conclusion, we see the need to focus on a struggle that continues to be active and that, despite the goals achieved, has still pending objectives.
\end{abstract}

Palabras clave:

homosexuales, discriminación, igualdad social, derechos humanos, discriminación sexual
Keywords:

homosexuals, discrimination, social equality, human rights, sex discrimination 


\section{Introducción}

“¡Joteamos, joteamos, pero también luchamos!” fue una de las consignas que se escuchó en la edición 2018 del Guadalajara Pride, en dicha ciudad del occidente de México. Este evento, sin lugar a duda, se configura como un grito de lucha que refleja la concepción que tiene la sociedad de la población LGBTI+, dando cuenta de que quienes están en esa marcha y alzando la voz son personas exigiendo al Estado que haga valer sus derechos en igualdad de condiciones.

Aunque pareciera que la lucha por los derechos de la comunidad LGBTI+ pudiera resultar un hecho muy actual, esto es algo alejado de la realidad, ya que la búsqueda de la igualdad por parte de los seres humanos es una visión tan antigua como el mismo momento en que se constituyó la sociedad. Sin embargo, y de manera concreta, la lucha social de la población LGBTI+ se ha enmarcado dentro de una evolución que migra de la clandestinidad de lo privado al espacio público, reclamando aquel sitio igualitario que otros grupos poblacionales han conseguido. En este contexto, y cumpliéndose cincuenta años de los representativos disturbios que se suscitaron a partir del allanamiento del bar Stonewall Inn en la ciudad de Nueva York el 28 de junio de 1969, es necesario analizar la visibilización del llamado gay power en el mundo, la región latinoamericana y, de manera concreta, en México, al ser un fenómeno social con un claro impacto en una población considerablemente representativa (Serrato y López, 2018).

Por ende, el presente artículo busca hacer una reflexión de los dos ámbitos en donde se ha cimentado la lucha por los derechos de la población LGBTI+ en México, considerando, en un primer momento, la lucha histórica en el espacio privado que han tenido que librar las personas homosexuales para, posteriormente, poder buscar su representatividad y voz en la esfera pública. Considerando que la última década ha tenido años que se han caracterizado por la lucha y el activismo social, pensamos que el presente artículo puede resultar valioso para ilustrar la razón de ser de los derechos de la comunidad LGBTI+ y el argumento que lleva a alzar la voz por los mismos. 


\section{La raíz de la represión, el pecado y el delito}

Para poder hacer un análisis cercano a la realidad de un país como México y su lucha por la igualdad de derechos de la comunidad LGBTI+, es necesario comprender la raíz de las creencias que argumentan sus acciones y el imaginario cultural. Para conseguir esto, y para los fines de este artículo, basta con considerar la imposición religiosa y axiológica que vino aparejada con la conquista militar española, la cual fue justificada a partir del mandato bíblico de expandir la fe cristiana y sobre la que se edificó la nueva sociedad colonial de la región. Esta nueva fe tenía un sustento teológico muy estructurado, el cual señalaba los parámetros de aquello que se debía considerar como correcto y premiable, e incorrecto y suprimible (Bidstrup, 2001).

En el terreno del ejercicio de la sexualidad, el poder establecido persiguió toda heterodoxia que dañara al modelo tradicional cristiano, que constituía y consagraba el matrimonio entre un hombre y una mujer bajo las leyes civiles y eclesiásticas. Se consideró también el sexo como impuro por excelencia y se le asoció con la mancha, el pecado y la culpa (Gruzinski, 1986). De esta forma, el adulterio, la bigamia, el amancebamiento, la prostitución, la homosexualidad y el incesto, como principales desviaciones sexuales, fueron fuertemente reprimidas y castigadas. Estas prácticas sexuales fueron consideradas como aberrantes y atentatorias del fin único de la sexualidad, el cual debía ser únicamente el de la reproducción a partir de la familia monogámica heterosexual, basada en la fidelidad y en el amor mutuo. La desviación con respecto a este modelo fue motivo de represión, persecución y castigo (Beccaria, 2001).

Pero, ¿cómo eran descubiertos estos desviantes por las autoridades? A finales del siglo XVIII, en el virreinato de la Nueva España, como en todo el imperio español, los infractores en materia sexual fueron identificados por el poder establecido a través de dos mecanismos:

mediante la delación de padres o madres, de vecinos, o de personas afectadas por pasiones como los celos, la envidia o la venganza, y por medio de la irrupción del poder estatal en la vida íntima, en el hogar de la vida cotidiana (Ortega, 1988, p. 17) 
En Guadalajara, por ejemplo, una denuncia era suficiente para iniciar una averiguación sobre un posible delito. Es ilustrativo el caso de un comerciante panameño, avecindado en esta ciudad, acusado por dos de sus empleados, sirvientes de su casa, "de haberles cometido el pecado nefando" (homosexualidad) en varias ocasiones, con violencia y "aprovechando la completa oscuridad de la noche" (BPEJ, s.f.). La denuncia era utilizada entonces como un importante instrumento de intimidación, ya fuera por parte, tanto de las autoridades como de los particulares, y fue ampliamente usada por quienes decidían aplicar a través de ella celos, venganzas o el deseo de afectar a otros.

Por otro lado, el concepto de pecado, dentro de la tradición cristiana, fue asociado a la sexualidad desde las enseñanzas de San Pablo en el siglo I, reafirmado por San Agustín y, principalmente, por Santo Tomás durante la Baja Edad Media. En la obra de este último, doctor de la Iglesia, descansaba la moral dominante en los países católicos y en los dominios de España durante la época colonial (Ortega, 1988). Se concibió entonces el ejercicio de la sexualidad como la impureza por excelencia y se le toleró por la consecuencia de la reproducción que de esta se derivaba y solo por esta circunstancia. De esta forma se asoció al sexo con el pecado.

En la sociedad colonial, la literatura y la iconografía de la época pretendió enseñar y mantener la idea del pecado asociado al ejercicio de la sexualidad. Los catecismos, los sermones publicados e infinidad de pinturas con temas religiosos y mundanos nos muestran cómo la sensualidad y el deseo sexual eran vehículos perfectos para la perdición de las almas e instrumentos favoritos del demonio para la consecución del mal (Gruzinski, 1986).

Sin embargo, fue a partir del siglo XIII cuando los discursos relativos a la estrecha unión entre la carnalidad y el demonio se incrementaron, quedando cada vez más evidente la figura de Satanás como inspirador del deseo sexual (Barrero, 2019). Esta situación llevó a los desviantes a tratar de ocultar su identidad y a resistir frente a una actitud hostil y calificadora de una sociedad represiva. Esta represión se extendió durante los siglos posteriores, dándose una mayor intervención del Estado dentro de estos aspectos en el contexto de la consolidación de los estados nacionales en Europa Occidental y también dentro de los procesos de secularización, en detrimento del poder tradicional de la Iglesia (Medina, 2016). 
Fue en esta época cuando se definió al criminal como enemigo de la sociedad, considerándose cada vez más al infractor como el causante de un mal no solo ante el individuo o la sociedad afectados, sino ante el rey, y en el caso de los delitos sexuales, también ante Dios. El castigo entonces no debía derivarse solo de la falta en sí, sino del daño causado a la sociedad, lo que justificaba un castigo que protegiese a la sociedad del criminal, aislándolo y poniendo en evidencia su culpa como ejemplo para los demás. Así pues, el ejercicio de la sexualidad no permitida era materia de moral; se le concebía como pecado y delito al mismo tiempo, cayendo de esta forma en materia de regulación y represión tanto de la esfera eclesiástica como de la civil (Barrero, 2019).

En el llamado "siglo de las luces", muchas transgresiones fueron sacadas poco a poco de la esfera del pecado hasta culminar el siglo XIX con la secularización de la mayoría de ellas. En las principales ciudades y en el extenso territorio del virreinato de la Nueva España también se persiguió a los desviantes en la búsqueda de "enderezar lo torcido" a partir de una perspectiva disciplinaria que tenía por función "reducir las desviaciones" (Foucault, 1984, p. 184).

De esta manera, se puede observar esta nueva disposición de las autoridades con relación a los castigos propuestos para los delitos de índole sexual. Por ejemplo, en un proceso realizado en Guadalajara en 1805 contra un militar llamado Apolinario Salmón, acusado de sodomía (práctica de la homosexualidad), se le permutó el castigo de "cien azotes en vía pública", "collar indecente" y "trabajo forzado en obra pública por cinco años". Se trataba de "regenerarlo" por medio del trabajo, según las nuevas ideas ilustradas, y no tanto el hecho de perseguir el castigo físico e infamante, aportando un servicio a la ciudad por medio del trabajo en la obra pública. Además, por su condición de militar, se buscaba "salvar el decoro y honor del batallón al que pertenecía" (BPEJ, 1805).

Así, el imaginario colonial produjo sus propios demonios y se encargó de satanizar a las minorías que estaban lejos del ideal moral católico. Los discursos relativos a las diversas manifestaciones de la sexualidad humana son prolíficos en calificativos de todo tipo, sobre la "monstruosidad" de múltiples actos perseguidos por la legislación colonial (Escobar, 2006). 
Entre las minorías perseguidas, los desviantes sexuales figuraron entre los más denunciados ante las autoridades. Aunque fue en las ciudades donde más se presentaron estos casos, se puede suponer que ocurrían en todo el extenso territorio virreinal. Las denuncias eran presentadas ante la autoridad inmediata y esta las encausaba ante los jueces de lo criminal (Vanegas y Suárez, 2008).

Fue en esta época, fines del siglo XVIII, cuando se agudizó el papel del Estado en lo relativo a reprimir a los desviantes sexuales, entre ellos los llamados sodomitas, tanto por la calidad de su desvío, es decir, la gravedad de la falta, como por su cantidad en cuanto al número creciente de infractores a la norma establecida; todo esto en el afán de perseguir y reprimir el "desorden” que provocaban en la sociedad (Valdés, 1981).

Así, los discursos de las autoridades civiles con respecto a las sexualidades consideradas desviadas se incrementaron a finales del siglo XVIII y principios del XIX, como un intento por parte del Estado por intervenir en la vida privada de los individuos y como consecuencia de las grandes transformaciones sociales de la época. Las ideas de la Ilustración, y posteriormente del liberalismo, eran recogidas y aceptadas por la autoridad con la consecuente búsqueda del bien del pueblo, pero desde el autoritarismo gubernamental que ejercía un papel paternalista sobre la población. La autoridad del Estado era indiscutible y tanto las instituciones como los individuos debían someterse a su poder (González, 1988).

Aun la Iglesia debió ceder terreno en su monopolio sobre la normatividad moral, al aceptar la jurisdicción del Estado en la persecución y castigo de las conductas sexuales desviadas (Connaughton, 1992). En las declaraciones de los acusados se determinaba su nombre, oficio, condición social y otros detalles sobre su vida, que nos hablan del interés de la autoridad por conocer muchos de los aspectos que "condicionaban" o "empujaban" a un individuo a cometer un delito. Esto permitió un mayor conocimiento que derivó en una gran cantidad de reglamentos que buscaban ordenar la vida de los individuos para formar una sociedad idealizada (Quinney, 1985). 
Resulta paradójico ver en esta profusión de reglamentos y normas (Viqueira, 1987) cómo las conductas desviantes se incrementaron y se extendieron, siendo tan solo el reflejo de la imposibilidad de contener y controlar el alud de situaciones contrarias al ideal cristiano que la autoridad se afanaba en imponer. Esta situación se extendió desde finales del siglo XVIII a buena parte del siglo XIX (una época de transición en lo político y social), cuando se intentó, de forma gradual, humanizar aun más la práctica de la justicia con respecto a los delitos de carácter sexual (Beccaria, 2001).

\section{Siglo XIX. La transición a una visión jurídica del homosexualismo}

El tránsito de la justicia antigua a la justicia moderna implicó el cambio gradual en la teoría y práctica jurídica. En el período de transición, que podemos establecer entre la segunda mitad del siglo XVIII y primera mitad del siglo XIX (González, 1988), se fue forjando un sistema judicial en el que se conjugaron elementos tradicionales y modernos. Con el impulso reformista de la época, que se centró principalmente en la consolidación del Estado sobre otras instituciones, se introdujeron también las preocupaciones por reformar el sistema jurídico imperante y por introducir aspectos más humanitarios en la práctica judicial.

En México, la Constitución de Cádiz de 1812 significó un importante momento en este proceso, pues incorporó algunos cambios en el ámbito de la justicia. Los cambios, dentro de lo que Francois-Xavier Guerra ha llamado la revolución liberal en el mundo hispánico (Ávila, 2004), llevaron también a un proceso inédito de discusión y reforma de los sistemas jurídico y penitenciario. En el caso de los delitos de carácter sexual se puede observar rupturas y continuidades de este proceso de transición en la práctica de la administración de la justicia.

Las infracciones a la moral dominante, así como el peligro social que significaban fueron las mismas durante todo el periodo virreinal, pero en las postrimerías del mismo ya eran sancionadas bajo diferentes criterios a los utilizados en los siglos anteriores. 
Había quienes buscaban implantar un sistema parecido al de Estados Unidos e Inglaterra que sujetara a los infractores en materia sexual y mantuviera mano firme contra los delincuentes. Sin embargo, también existía una preocupación por crear un sistema penal moderno y más humanitario en el que se descartara la tortura y los castigos corporales, y que defendiera al reo hasta la comprobación del delito (Suárez, 1999).

En el discurso moderno, no tanto en la práctica, se discutió mucho sobre el individuo y la necesidad de regeneración en una sociedad preocupada por salir de "las tinieblas" del período virreinal. Como ya se señaló, el delito de sodomía (ya conceptualizado desde una óptica médica y pretendidamente científica como homosexualidad a partir de la segunda mitad del siglo XIX) siguió considerándose dentro del ámbito criminal y las infracciones en esta materia como atentatorias de la moral y del orden social (Valdés, 1981).

La práctica de la homosexualidad continuó considerándose como fuente de escándalo puesto que atentaba contra el orden social, tal como se entendía entonces, tanto antes como después de la independencia. Pocas modificaciones pueden observarse desde la letra de la ley, en donde los cambios significativos solo se presentan en cuanto a la realización formal de los procesos judiciales. Durante todo este período, la práctica de la homosexualidad continuó siendo perseguida entendiéndose como "el acceso carnal entre personas del mismo sexo o en vaso indebido" (Escriche, 1996, p. 648).

El derecho de transición (de finales del siglo XVIII a principios del siglo XIX) visto a la luz de los delitos de carácter sexual analizados en este texto, refleja importantes cambios en la mentalidad y en la decisión de cambiar el sistema judicial heredado de la época virreinal, sin embargo, las difíciles condiciones políticas y sociales de la primera mitad del siglo XIX no permitieron grandes avances en la práctica judicial (González, 1988). 
Aunque en el siglo XX no se puede señalar que haya habido un cambio decisivo en materias judiciales relacionadas con crímenes sexuales, este nuevo centenario tuvo un inicio enmarcado por una mayor lucha por la visibilización de la comunidad homosexual. Ejemplo de esto fue el llamado "baile de los cuarenta y uno" el dieciocho de noviembre de 1901 que terminó con una redada policial en la Ciudad de México contra un baile de hombres en una vivienda particular, en el cual diecinueve de ellos se encontraban vestidos de mujer. A pesar de que el gobierno de la época trató de ocultar el asunto, por ser hombres de la clase alta de la sociedad porfiriana, el impacto mediático fue mayor, lo cual abrió la necesidad de hablar de un tema que por años se había restringido a las clases bajas y poco educadas (Monsivaís, 2001).

Días posteriores al hecho, la intervención policíaca fue calificada de ilegal y arbitraria, ya que violaba los derechos humanos y civiles de los agraviados. Aunque se argumentó que la celebración iba en contra de la moral y las buenas costumbres, ninguna disposición jurídica de la época mencionaba una posible pena hacia los detenidos, quienes terminaron, en algunos de los casos, realizando trabajos a favor de la comunidad en el Puerto de Progreso (Barrón, 2010). No obstante, se cuestionaba que los únicos sentenciados eran aquellos que no habían podido pagar por salir libres. En ese mismo año, pero el cuatro de diciembre, hubo una redada en un local de mujeres lesbianas en la misma Ciudad de México, sin embargo, no tuvo el mismo impacto social.

A partir de estos sucesos, las redadas, chantajes policíacos, torturas y aprisionamientos por parte de la policía a las personas homosexuales se volvió cada vez más usual, aunque colocó a la sociedad mexicana frente a un tema que se negaba a aceptar en un ambiente fuertemente conservador. Bastaron un par de décadas para que la influencia internacional y las luchas por los derechos de las minorías comenzarán a hacer eco en México, abriendo así una pauta para los primeros pasos de un posible activismo mexicano. 


\section{Re-construyendo la realidad: el nacimiento de una lucha LGBTI+}

Después de la Segunda Guerra Mundial, la comunidad internacional puso mayor atención en los derechos humanos de los grupos minoritarios, entre los cuales, lógicamente, se encontraba la población homosexual. Pero, a pesar de esto, la Asociación Americana de Psiquiatría seguía considerando la homosexualidad como un trastorno sociopático de la personalidad, lo cual estereotipaba gravemente al homosexualismo.

Aun así, fueron diferentes las reacciones que se suscitaron y que buscaban defender los derechos de los homosexuales a nivel internacional. En 1950, se funda la organización "Sociedad Mattachine" como el primer grupo organizado para defender sus de derechos, a esta le siguió las "Hijas de Bilitis", organización fundada en San Francisco que veía por los derechos lésbicos. Poco a poco, la voz de la comunidad LGBTI+ se fue haciendo más fuerte, consiguiendo que países como Reino Unido derogaran sus leyes contra la sodomía en 1967 e impulsando la lucha internacional por lograr un trato igual para todos aquellos que no se apegaban a la heteronormatividad establecida (Bidstrup, 2001).

Sin lugar a duda, uno de los momentos que más marcó la historia de este grupo fue el del veintiocho de junio de 1969, cuando los clientes del bar Stonewall Inn en Greenwich Village, Nueva York, se revelaron en contra de la policía por el acoso que como comunidad sufrían por parte de esta institución (Giraldo, 1971). Las protestas duraron días y sentaron el precedente de la necesidad de manifestarse por la defensa de sus derechos. Un año posterior a estos acontecimientos, miles de personas de la comunidad LGBT+ marcharon por la ciudad de Nueva York conmemorando los disturbios y estableciendo que, sin importar su orientación sexual, contaban con los mismos derechos (Díaz, 2004). 
Este suceso fue la pauta para cuatro elementos primordiales que establecerían la directriz del movimiento LGBTI+. El primero de ellos fue exponer las acciones represivas y discriminatorias, principalmente del Estado hacia la población de la diversidad sexual, y exigir un goce de derechos como cualquier otra persona. En segundo lugar, fue un punto de quiebre para el status quo porque, si bien había graves ataques hacia las personas de la diversidad sexual y privación de sus derechos fundamentales, el silencio era el que había prevalecido hasta entonces (Cornejo, 2007).

Asimismo, y como tercer elemento, estos disturbios fueron un referente para que la población LGBTI+ de otras regiones del hemisferio occidental se organizaran, dejaran el anonimato y tomaran la decisión de participar en la agenda pública; como lo fue el caso de México, en donde comienzan a surgir, a partir de 1980, las primeras organizaciones o colectivos para hacer frente a las represiones de homosexuales, travestis y lesbianas (Lázaro, 2014). Por último, como cuarto elemento, se encuentra la identidad cultural para la conmemoración del orgullo por la diversidad sexual, toda vez que quedó instaurado que cada veintiocho de junio se celebraría el "Día del Orgullo Gay".

Estos inicios del activismo LGBTI+ estuvieron enmarcados en un contexto sociocultural y político de conciencia cívica por ciertos acontecimientos a nivel global: la exigencia de los derechos civiles y políticos de la población afroamericana, los movimientos estudiantiles de 1968-Francia, México y Argentina, por mencionar algunos-, la Primavera de Praga de la entonces Checoslovaquia, la Revolución Cubana, así como la liberación sexual, el feminismo y la revolución cultural denominada "el movimiento hippie". Estos mecanismos de transformación social contribuyeron a darle una base ideológica al movimiento LGBTI+, no en el sentido de adoptar una doctrina de socialismo o capitalismo, sino de tener referencias de movilizaciones que pusieran fin a la marginación, discriminación, exclusión y opresión por parte de las autoridades del Estado y de la misma sociedad (Vespucci, 2011). 
Desde que comenzó el activismo LGBTI+, este se convirtió en un movimiento que trascendió el contexto local para proyectarse a nivel regional y global buscando el restablecimiento de los derechos constitucionales y humanos para las personas de la diversidad sexual (Lázaro, 2014). En ese trayecto de expansión y de suma de esfuerzos a través de colectivos y organizaciones de los diferentes países, Ch. A. Lázaro (2014) apunta que el activismo ha concentrado su lucha en:

- $\quad$ La despenalización de la homosexualidad.

- $\quad$ La visibilidad individual y colectiva de la población diversa.

- $\quad$ La represión del Estado y la sociedad hacia la homosexualidad.

- $\quad$ Las estrategias de educación socio-sexual (lucha contra el VIH/SIDA).

Como un ejemplo de esta nueva visión de lucha surge, en 1978, la Asociación Internacional de Lesbianas, Gays, Bisexuales, Trans e Intersex (ILGA) para fungir como una red aglutinadora de grupos que trabajaran a nivel nacional y local en el tema de la igualdad de derechos para la población de diversidad sexual en todo el mundo. Hasta hoy en día, esta es la red más grande de organizaciones y colectivos que ha sido capaz de posicionar la agenda LGBTI+ en el ámbito internacional (Bidstrup, 2001).

La década de los 80 fue un período de golpe para el activismo LGBT+. Esto sucede porque el cinco de junio de 1981 los Centros para el Control y Prevención de Enfermedades de Estados Unidos dieron a conocer lo que parecía un nuevo virus que ocasionaba neumonía y sarcomas en la piel de la persona infectada de VIH. Además, aparecían manchas color rosáceo lo que hizo que los medios de comunicación la llamaran la "peste rosa", asociándola directamente a los homosexuales (Calcsicova, 2016). Sin embargo, fue hasta mayo de 1983 que dicho padecimiento recibió el nombre de Virus de Inmunodeficiencia Humana (VIH), lo cual hacía que se desarrollara el Síndrome de Inmunodeficiencia Adquirida, SIDA (Linde, 2018).

Esta noticia fue tomada por los medios de comunicación para contribuir a la estigmatización social de los grupos de la diversidad sexual, particularmente, los homosexuales. 
De ahí que las organizaciones y colectivos locales, nacionales e internacionales tuvieran que encauzar esfuerzos en combatir la desinformación, los discursos condenatorios y la invalidación de la lucha por la conquista de una igualdad en derechos, que había comenzado años atrás.

A pesar de esta fase crítica para el movimiento de la diversidad sexual, este continuó su trabajo a través de esas "luchas colectivas que han progresado en los últimos decenios bajo la defensa de los derechos humanos, reivindicando un conjunto de derechos por el reconocimiento y la no discriminación" (López, 2018, p. 1). En los años noventa se dio un incremento de las protestas contra la violencia hacia las personas LGBTI+, lo que originó el establecimiento de un discurso de igualdad y no-discriminación (Weis, 2014). Este incremento de protestas también significó una consolidación del movimiento LGBT+ a nivel mundial.

A inicios del siglo XXI se originó otro avance para la población LGBT+ gracias al activismo de cientos de organizaciones en el comienzo de la legislación del matrimonio igualitario. Este ha sido uno de los temas coyunturales que se ha posicionado en el espacio político de las naciones, puesto que, en tanto existan las condiciones jurídicas para el matrimonio entre personas del mismo sexo, será posible garantizar el goce de los derechos que ya disfruta una pareja heterosexual (Peinado, 2009).

Empero, hoy en día la lucha LGBTI+ y su activismo van más allá del matrimonio igualitario. En la actualidad se ha trabajado para darle visibilidad a aquellos grupos que se han relegado a la clandestinidad y que han padecido el recrudecimiento de la discriminación, el rechazo y el odio: las personas transgénero (Sánchez, 2011). De acuerdo al Observatorio de Personas Trans Asesinadas, de octubre de 2017 a septiembre de 2018 hubo un total de trescientos sesenta y nueve casos de homicidios reportados de personas trans y género-diversas (TGEU, 2019), siendo Brasil y México los dos primeros países donde más ocurren estos asesinatos. Parte importante del activismo en este sentido está relacionado con el trato mediático que se le da a estos casos, donde re-victimizan y violentan la identidad de la persona como en su momento se llevaba a cabo con el homosexualismo. 
En este sentido, la Asociación Gay y Lésbica contra la Difamación (o GLAAD por sus siglas en inglés), también dedicada a compartir historias de la población LGBTI+ a través de noticias y medios digitales como una apuesta para acelerar la inclusión de la diversidad, ha declarado seis elementos vertebrales para dar cobertura de forma objetiva y respetuosa a los temas de personas transgénero: 1) no usar lenguaje problemático; 2) no usar caracterizaciones difamatorias; 3) no poner énfasis en las operaciones médicas y genitales; 4) usar el nombre que escogió la persona transgénero; 5) en caso de que la persona hubiera sido víctima de crimen, averiguar cómo se identificaba; 6) no usar pronombres o artículos incorrectos (GLAAD, s.f.).

Acciones como estas son las que han hecho que el activismo LGBTI+ incida de manera positiva en una transformación social incluyente, respetuosa de la diversidad y libre de violencia. Asimismo, la lucha por los derechos de la población LGBTI+ no solo ha hecho uso del espacio público para reclamar esas condiciones de igualdad, sino que ahora se ha valido de las plataformas digitales y otras estrategias para crear una sensibilidad de lo que viven en el día a día las personas LGBTI+ y, a la vez, propiciar una conciencia que genere empatía y cuestione los constructos sociales en los que cada persona está inmersa. Estrategias actualmente usadas por el activismo contemporáneo.

\section{Conclusiones}

\section{Reflexión de cierre. Una lucha que continúa con nuevos retos}

Durante este trayecto de dar un vistazo a lo que ha sido el desarrollo de la lucha por la igualdad de la comunidad LGBTI+, es posible notar el factor común que ha estado presente en cada una de las etapas desde su gestación hasta la actualidad: visibilizar la opresión, la segregación y la desigualdad que puede sufrir una persona por su orientación sexual o identidad de género. Este recorrido se trata de voltear a ver las raíces del movimiento para que las nuevas generaciones de personas LGBTI+ reconozcan el trabajo previo y el camino recorrido, y recuerden que los derechos logrados no sucedieron por el hecho de simplemente declararlos. 
Asimismo, existe el reto de mejorar las condiciones en las que se da el activismo, considerando los desencuentros que pueden darse, derivados de las diferentes posturas que tienen las organizaciones o colectivos al momento de abordar las diversas problemáticas que aquejan a este sector de la población. Esta misma desarticulación lo que provoca es el aislamiento de otras luchas que suceden en el contexto de los derechos humanos, construyendo una barrera que impide solidarizarse con movimientos como los de las personas con discapacidad, las trabajadoras del hogar, los migrantes, las desapariciones forzadas y la violencia de género. Si bien es cierto que se trata de sectores de la población con necesidades particulares, también es cierto que es necesario impulsar una agenda consensuada, unificada y de alto impacto para incidir social, política y culturalmente y no diluir los esfuerzos colectivos que abonan a la construcción de una realidad diferente.

Además, es necesario que se prevea que esta lucha no está terminada, pues aún resta la generación de espacios verdaderamente seguros en el que se pueda hablar y vivir con libertad sin padecer agresiones o amenazas. El reto es construir estos entornos de vivencia y respeto a la diversidad, tanto en ámbitos públicos como privados, haciendo conciencia social que no se trata de privilegios ni de mayores derechos, sino de gozar de aquellos que las personas heterosexuales ya tienen. Mientras llega ese momento, continuará existiendo el activismo y su pluralidad como una forma de activar la esperanza de una transformación social, ya que la lucha de la comunidad LGBTI+ aún sigue activa y viendo por un futuro igualitario e incluyente para todas y todos. 


\section{Referencias}

Ávila, A. (2004). De las independencias a la modernidad. Notas sobre un cambio historiográfico. En F. X. Guerra, Conceptualizar lo que se ve (pp. 68-93). México: Instituto de Investigaciones Dr. José María Luis Mora.

Barrero, A. (2019). Cuando amar era pecado. Sexualidad, poder e identidad entre los sodomitas coloniales. Fronteras de la Historia, 24(1), 164-168.

Barrón, M. (2010). El baile de los 41: la representación de lo afeminado en la prensa porfiriana. Historia y grafia (34), 47-73.

Beccaria, C. (2001). Tratados de los delitos y de las penas. México: Porrúa.

Bidstrup, S. (2001). Homosexualidad en la historia. Buenos Aires, Argentina: Sociedad de Integración Gay Lésbica Argentina. Recuperado de http:// www.sigla.org.ar/index.php?option=com_content\&view=article\&id=91: homosexualidad-en-la-historia-parte-1\&Itemid=104

Biblioteca Pública del Estado de Jalisco (BPEJ). (1805). El alcalde de 2o. voto contra José Nabor de la Encarnación y Apolinario Salmón por Sodomía y otros excesos. Guadalajara: Archivo de la Real Audiencia.

Biblioteca Pública del Estado de Jalisco (BPEJ). (s.f.). Archivo del Supremo Tribunal de Justicia. Ramo Criminal. Guadalajara.

Coordinadora de Asociaciones de Lucha contra el Sida de la Comunidad de Valencia (CALCSICOVA). (2016). Historia del VIH y el SIDA. Valencia, España: CALCSICOVA. Recuperado de http://www.calcsicova.org/ es/historia-del-vih-y-el-sida

Connaughton, B. (1992). Ideología y sociedad en Guadalajara (1788-1853). México: Consejo Nacional para la Cultura y las Artes. 
Cornejo, J. (2007). La homosexualidad como una construcción ideológica. Límite, 2(16), 83-108.

Díaz, M. (2004). Homosexualidad y género. Cuicuilco, 11(31), 1-13.

Escobar, M. (2006). Sexualidad y mitos en el México Colonial. En M. Herrera, Estudios históricos sobre las mujeres en México (pp. 79-88). Puebla, México: BUAP.

Escriche, J. (1996). Diccionario razonado de legislación civil, penal, comercial y forense. México: Universidad Nacional Autónoma de México.

Foucault, M. (1984). Vigilar y castigar: nacimiento de la prisión. México: Siglo XXI Editores.

Giraldo, O. (1971). Investigaciones y teorías sobre homosexualidad masculina. Revista Latinoamericana de Psicología, 3(3), 237-296.

Gay and Lesbian Alliance Against Defamation (GLAAD). (S.F.). Guía para una Cobertura Objetiva de Personas y Temas Transgénero. Los Ángeles, Estados Unidos: GLAAD. Recuperado de https://www.glaad. org/publications/gu\%C3\%ADa-para-una-cobertura-objetiva-de-personasy-temas-transg $\% \mathrm{C} 3 \% \mathrm{~A} 9$ nero

González, M. (1988). El derecho de transición. El derecho civil en México, 1821 1871. México: Universidad Nacional Autónoma de México.

Gruzinski, S. (1986). Las cenizas del deseo. Homosexuales novohispanos a mediados del siglo XVII. En S. Ortega, De la santidad a la perversión o de por qué no se cumplía la ley de Dios en la sociedad novohispana (pp. 255-290). México: Grijalbo.

Lázaro, C. (2014). La conformación del movimiento LGBT en Guadalajara, Jalisco. Argumentos, 27(76), 241-273. 
Una aproximación histórico-social...

Linde, P. (18 de Mayo de 2018). 35 años del descubrimiento de aquel extraño y mortal virus. El País. Recuperado de https:/elpais.com/ elpais/2018/05/16/planeta_futuro/1526425640_348314.html

López, J. (2018). Movilización y contramovilización frente a los derechos LGBTI. Respuestas conservadoras al reconocimiento de los derechos humanos. Estudios sociológicos, 36(106), 161-187.

Medina, S. (2016). El control social del virreinato novohispano: las dos majestades en el dispositivo judicial. Heurística Jurídica 1(3), 151-158.

Monsivaís, C. (8 de Noviembre de 2001). La gran redada. La Jornada. Recuperado de https://www.jornada.com.mx/2001/11/08/ls-monsivais. html

Ortega, S. (1988). El discurso teológico de Santo Tomás de Aquino sobre el matrimonio, la familia y los comportamientos sexuales. En El placer de pecar y el afán de normar (pp. 14-36). México: Joaquín Mortíz.

Peinado, M. (2009). En torno a la homosexualidad en educación para al ciudadanía. Enseñanza de las Ciencias Sociales, (8), 67-73.

Quinney, R. (1985). Clases, Estado y delincuencia. Mexico: Fondo de Cultura Económica.

Sánchez, C. (2011). ¿Marchar o no marchar? Esa es la cuestión: movilización legar en tiempos de agitación para los sectores LGBT en Colombia. Revista VIA IURIS (10), 157-166.

Serrato, A. y López, E. (2018). Del coming out a los derechos humanos en las demandas de las organizaciones de la sociedad civil del movimiento LGBT: estrategias discursivas de refugio. Andamios, 15(37), 119-144. 
Suárez, M. (1999). Sexualidad y norma sobre lo prohibido. La Ciudad de México y las postrimerías del virreinato. México: Universidad Autónoma Metropolitana.

Transgender Europe (TGEU). (2019). Observatorio de Personas Trans Asesinadas. Berlín, Alemania: Transgender Europe. Recuperado de https://transrespect.org/es/map/trans-murder-monitoring/

Valdés, A. (1981). Historia y presente de la homosexualidad. Madrid: Akal.

Vanegas, D. y Suarez, O. (2008). Evolución del sistema penal acusatorio en el marco del derecho germano, anglosajón y colombiano. Misión Jurídica, 1(1), 89-108.

Vespucci, G. (2011). Explorando un intrincado triángulo conceptual: homosexualidad, familia y liberación en los discursos del Frente de Liberación Homosexual de Argentina. Historia Crítica, (43), 174-197.

Viqueira, J. (1987). ¿Relajados o reprimidos? Diversiones públicas y vida social en la ciudad de México durante el siglo de las luces. México: Fondo de Cultura Económica.

Weis, R. (2014). El activismo LGBT en México: nuevos retos ... viejas amenazas. Ciudad de México: Heinrich-Böll-Stiftung. Recuperado de https://mx. boell.org/es/2014/10/27/el-activismo-lgbt-en-mexico-nuevos-retos-viejasamenazas 